TITLE: Restructuring of the Healthcare System in Italy during COVID-19: An Organizational

\title{
Ethics Dilemma
}

AUTHOR: Ziad Sabaa-Ayoun

This article is a pre-print. The final version can be found in issue $89(\mathrm{~S})$. 


\begin{abstract}
The rise of the novel coronavirus disease 2019 (COVID-19) caused unprecedented public health responses worldwide. To prevent hospitals from oversaturating, nations are restructuring their healthcare systems to prioritize limited resources and care for the treatment of COVID-19-infected patients. The Italian healthcare system, for example, converted numerous hospital services to Intensive Care Units, redeployed physicians to short-staffed centers, and centralized medical services to a small number of hospitals to meet the pandemic's demands. While this restructuring served the nation's short-term healthcare needs, it impeded access to care for non-COVID-19 patients suffering from acute or chronic non-communicable diseases, such as strokes. These patients are at increased risk of long-term disability and poorer adherence to management plans and have an increased likelihood of disease recurrence. This commentary discusses the ethical dilemma surrounding the necessary healthcare restructuring and unintended impairment of care to non-infected patients. It also explores the need for national public health officials to reassess strategies employed during the pandemic and their need to focus on creating ethical frameworks for maximizing equitable care.
\end{abstract}


On December 31, 2019, the first report concerning coronavirus disease 2019 (COVID-19) reached the World Health Organization (WHO). ${ }^{1}$ On March 11, 2020, the WHO declared COVID-19 a global pandemic, which has led to an unprecedented international public health response. ${ }^{2}$ At the national level, countries were forced to make the difficult, yet necessary, decision to reorganize their healthcare systems to increase COVID-19 treatment resources. ${ }^{3}$

At its core, nations have reorganized their healthcare systems to prioritize care for the most resource intensive and pressing problem: the treatment of COVID-19-infected patients. ${ }^{3}$ As cases quickly accumulated, the risk of oversaturating hospitals increased because of limited Intensive Care Unit (ICU) beds, ventilators, and staff. ${ }^{4}$ The pandemic's intensity left healthcare systems worldwide unprepared to account for the rapidly deteriorating situation, straining their limited resources. These conditions forced healthcare providers to make ethically challenging decisions when allocating resources to patients. ${ }^{3,5}$ As such, there was an immediate need to mobilize resources to minimize inefficient treatment. ${ }^{4}$

To better meet the needs of the pandemic, regional authorities created ethical guidelines to prioritize limited resources, such as preferentially admitting patients who had better chances of recovery. ${ }^{5,6}$ Many hospitals modified and converted regular day-to-day operations to increase ICU availability. ${ }^{7,8}$ While such systemic conversions served the needs at hand, they also introduced their own set of challenges that could result in increased rates of morbidity and mortality among non-COVID-19 patients. $^{8}$ For example, non-infected patients suffering from cardiovascular or cerebrovascular conditions experienced interruptions in care, thus complicating their recovery. ${ }^{8}$ Therefore, while such ad hoc restructuring may be ethically necessary in cases of extreme shortage, it is not a single-faceted approach, and care should be taken to avoid unnecessary medical complications. 
Generally, Italy, is highly regarded for its universal healthcare system, operating at a laudable 3.2 hospital beds and 4.0 physicians for every 1000 people. ${ }^{9,10}$ Nevertheless, Italy has become an example of a state pushed past its breaking point. ${ }^{8}$ Specifically, from April until May 2020, the country had the second-highest number of total COVID-19 incidences among all European countries, and had reached 251,713 confirmed cases and 35,225 deaths, as of August $13,2020 . .^{11-13}$

To mitigate an impending oversaturation of its healthcare system, Italy required the quick mobilization of resources for infected patients. This process involved converting medicine wards, operating rooms, and numerous hospital services into additional ICUs. ${ }^{3,4,8,14}$ Namely, the centres converted into dedicated COVID-19 units included neurological services, such as stroke care units and neurointensive care units, as well as cardiac care centres..$^{3,8,15,16}$ Further, physicians from various medical specialties were redeployed from their respective services to help meet staff demands on the frontline, assisting directly with triage and care for infected patients. $3,8,14$ For example, cardiologists in some hospitals were tasked to work in emergency room settings. ${ }^{14}$ Other physicians had been relocated to areas of the country that were short-staffed..$^{3,8,14}$ Subsequently, specialties requiring multidisciplinary teams were negatively impacted by the staff redeployment. ${ }^{3,8}$ In another measure, Italy designated certain hospitals to care only for noninfected patients and centralized many medical services to these hospitals, effectively reducing the number of services available..$^{3,7,8,17}$ The remaining hospitals existed exclusively for the care of infected patients. ${ }^{3,7,8,17}$

Italy's restructuring, however, came at a cost to many non-COVID-19 patients seeking acute care, as it significantly reduced access to treatment. ${ }^{8}$ To highlight, reports noted a 26-30\% decrease in the administration of acute stroke therapies during the months of the 
pandemic, in comparison to the same time in $2019 .{ }^{18}$ This can be attributed to several reasons. Firstly, fewer stroke centers were available for patients. ${ }^{3,8,19}$ For example, in the Lombardy region of Italy, a total of 11 out of 36 stroke centers remained open. ${ }^{8}$ Secondly, centralization of the remaining stroke units and emergency rooms to limited locations resulted in patient overcrowding at these sites. ${ }^{8}$ Thirdly, physician redeployment severely reduced the number of patient consultations and neurological examinations that could occur. ${ }^{8}$ As a result, patients experienced longer wait times and door-to-treatment times, which delayed crucial reperfusion therapy for acute stroke care and increased the risk of long-term damage. ${ }^{18,20,21}$ Additionally, overcrowding likely deterred patients from presenting to the hospital due to the increased risk of infection. ${ }^{22}$ As a result, symptoms of stroke were left unrecognized or untreated, and hospitals observed a 50\% decrease in minor stroke or transient ischemic attack admissions during the months of the pandemic, as compared to the same time in $2019 .{ }^{18}$ Similar trends were observed in patients suffering from cardiovascular disease. ${ }^{16,20}$

The prioritization of COVID-19 care also affected non-infected patients suffering from chronic conditions. ${ }^{8}$ Specifically, rehabilitation services and follow-up appointments were limited to reduce unnecessary viral exposure. ${ }^{8}$ For example, stroke survivors often require a multidisciplinary approach in order to regain physical strength and coordination, resume activities of daily living, prevent stroke recurrence, and improve mental wellbeing. ${ }^{23}$ Limited access to these services impaired crucial rehabilitation management. ${ }^{8}$ This could result in continued disability and poorer adherence to secondary prevention strategies, which would increase the likelihood of recurrence and affect patients' mental wellness. ${ }^{21,23}$ 
Beyond introducing challenges to healthcare management, COVID-19 has also introduced a myriad of ethical questions on topics such as hospital and healthcare system preparedness during times of crisis. There is no doubt that, to survive the drastic impact of the pandemic, emergency restructuring was necessary, following a utilitarian approach. ${ }^{24}$ Namely, the resources were maximized for the greatest number of individuals. ${ }^{24}$ However, the unprecedented nature of the pandemic left many nations unprepared to face a challenge of this magnitude, resulting in the unintended impairment of care to non-COVID-19 patients. ${ }^{25}$ Given that cerebrovascular and cardiovascular diseases are among the two leading causes of death worldwide, and rates of both have been found to affect and be affected by COVID-19, it is just as important to maintain ongoing, accessible care for these patients as well. ${ }^{26-29}$ Therefore, the ethical question is not whether a nation should restructure, but rather how it should restructure in order to minimize morbidity and mortality for both infected and non-infected patients alike.

As countries begin easing lockdown measures, it is crucial for public health authorities and elected officials to reflect on the successes and challenges of the previous months' strategies. It is necessary to consult with healthcare practitioners, establish registries for non-communicable diseases such as stroke, focus on demographic and socioeconomic disparities, and to combine these strategies to create an ethical framework that can be applied to maximize resource allocation. Ultimately, the goal being to provide equitable access to care for the most patients moving forward. 


\section{REFERENCES}

1. World Health Organization (WHO). Pneumonia of unknown cause - China [Internet]. Switzerland: World Health Organization; 2020 January 5 [cited 2020 June 23]. Available at: https://www.who.int/csr/don/05-january-2020-pneumonia-of-unkown-cause-china/en/.

2. Cucinotta D, Vanelli M. WHO Declares COVID-19 a pandemic. Acta Biomed. 2020 March 19;91:157-60. https://doi.org/10.23750/abm.v91i1.9397

3. Bersano A, Pantoni L. On being a neurologist in Italy at the time of the COVID-19 outbreak. Neurology. 2020 May 26;94:905-6. https://doi.org/10.1212/WNL.0000000000009508

4. Remuzzi A, Remuzzi G. COVID-19 and Italy: what next? Lancet. 2020 April 11;395:1225-8. https://doi.org/10.1016/S0140-6736(20)30627-9

5. Mounk Y. The Extraordinary Decisions Facing Italian Doctors [Internet]. Washington (DC): The Atlantic; 2020 March 11 [cited 2020 June 23]. Available from: https://www.theatlantic.com/ideas/archive/2020/03/who-gets-hospital-bed/607807/.

6. SIAARTI. Raccomandazioni di etica clinica Per l'ammissione a trattamenti intensivi e per la loro sospensione, In condizioni eccezionali Di squilibrio tra necessità E risorse disponibili [Internet]. Italy: SIAARTI; 2020 March 6 [cited 2020 June 23]. Available from: http://www.siaarti.it/SiteAssets/News/COVID19\%20\%20documenti\%20SIAARTI/SIAARTI\%20-\%20Covid19\%20\%20Raccomandazioni\%20di\%20etica\%20clinica.pdf.

7. La Giunta di Regione Lombardia. ULTERIORI DETERMINAZIONI IN ORDINE ALL'EMERGENZA EPIDEMIOLOGICA DA COVID-19 [Internet]. Italy: La Giunta di Regione Lombardia; 2020 March 8 [cited June 23, 2020]. Available from: 
https://www.regione.lombardia.it/wps/wcm/connect/5e0deec4-caca-409c-825b-

25f781d8756c/DGR+2906+8+marzo+2020.pdf?MOD=AJPERES\&CACHEID=ROOTW

ORKSPACE-5e0deec4-caca-409c-825b-25f781d8756c-n2.vCsc.

8. Bersano A, Kraemer M, Touze E, et al. Stroke care during the COVID-19 pandemic: experience from three large European countries. Eur J Neurol. 2020 June 3:1-7. https://doi.org/10.1111/ene.14375

9. Pflanzer LR. Here's why experts are worried we won't have enough hospital beds to handle a surge of coronavirus patients [Internet]. New York City (NY): Business Insider; 2020 March 19 [cited June 23, 2020]. Available from:

https://www.businessinsider.com/coronavirus-hospital-beds-per-capita-us-south-koreaitaly-2020-3.

10. Kamal R, Kurani N, McDermott D, et al. How prepared is the US to respond to COVID19 relative to other countries? [Internet]. New York City (NY): Health System Tracker; 2020 March 27 [cited June 23, 2020]. Available from:

https://www.healthsystemtracker.org/chart-collection/how-prepared-is-the-us-to-respondto-covid-19-relative-to-other-countries/\#item-practicing-physicians-per-1000-population2017-or-nearest-year.

11. Coronavirus disease 2019 (COVID-19) Situation Report - 76 [Internet]. Switzerland: World Health Organization. 2020 April 5 [cited 2020 August 7]. Available from: https://www.who.int/docs/default-source/coronaviruse/situation-reports/20200405-sitrep76-covid-19.pdf?sfvrsn=6ecf0977_4

12. Coronavirus disease 2019 (COVID-19) Situation Report - 111 [Internet]. Switzerland: World Health Organization. 2020 May 10 [cited 2020 June 28]. Available from: 
https://www.who.int/docs/default-source/coronaviruse/situation-reports/20200510covid19-sitrep-111.pdf?sfvrsn=1896976f_6.

13. Coronavirus disease 2019 (COVID-19) Situation Report - 206 [Internet]. Switzerland: World Health Organization. 2020 August 13 [cited 2020 August 13]. Available from: https://www.who.int/docs/default-source/coronaviruse/situation-reports/20200813-covid19-sitrep-206.pdf?sfvrsn=bf38f66b_6.

14. Parodi E, Alioisi S, Barbaglia P. 'All is well': triage and lies await Italy's critical coronavirus patients [Internet]. Global News. 2020 March 16 [cited June 23, 2020]. Available from: https://globalnews.ca/news/6686078/coronavirus-italy-lies-patientscovid/.

15. Indolfi C, Spaccarotella C. The outbreak of COVID-19 in Italy. J Am Coll Cardiol Case Rep. EPub 2020 April 29. https://doi.org/10.1016/j.jaccas.2020.03.012.

16. Stefanini GG, Azzolini E, Condorelli G. Critical organizational issues for cardiologists in the COVID-19 outbreak. Circulation. 2020 March 24;141:1597-1599. https://doi.org/10.1161/CIRCULATIONAHA.120.047070.

17. Spina S, Marrazzo F, Migliari M, Stucchi R, Sforza A. The response of Milan's emergency medical system to the COVID-19 outbreak in Italy. Lancet. Epub 2020 February 28;395:e49-e50. https://doi.org/10.1016/s0140-6736(20)30493-1.

18. Baracchini C, Pieroni A, Viaro F, et al. Acute stroke management pathway during Coronavirus-19 pandemic. Neurol Sci. 2020 April 9;41:1003-1005. https://doi.org/10.1007/s10072-020-04375-9. 
19. Caso V, Federico A. No lockdown for neurological diseases during COVID19 pandemic infection. Neurol Sci. 2020 April 8;41:999-1001. https://doi.org/10.1007/s10072-02004389-3.

20. Butler-Jones D, Simard A. Don't wait for COVID-19 to end to address health concerns. [Internet]. Ottawa (ON): Heart and Stroke Foundation; 2020 May 12 [cited June 23, 2020]. Available from: https://www.heartandstroke.ca/articles/don-t-wait-for-covid-19to-end-to-address-health-concerns.

21. Lavallée PC, Meseguer E, Abboud H, et al. A Transient Ischaemic Attack Clinic With Round-The-Clock Access (SOS-TIA): Feasibility and Effects. Lancet Neurol. 2007 Nov $1 ; 6: 953-60$. https://doi.org/10.1016/S1474-4422(07)70248-X.

22. Abootalebi S, Aertker BM, Andalibi MS, et al. Call to Action: SARS-CoV-2 and CerebrovAscular DisordErs (CASCADE). J Stroke Cerebrovasc Dis. 2020 Sep;29:104938. https://doi.org/10.1016/j.jstrokecerebrovasdis.2020.104938.

23. Office of Communications and Public Liaison. Post-Stroke Rehabilitation Fact Sheet [Internet]. Bethesda (MD): National Institute of Neurological Disorders and Stroke; 2020 [cited June 23, 2020]. Available from: https://www.ninds.nih.gov/Disorders/PatientCaregiver-Education/Fact-Sheets/Post-Stroke-Rehabilitation-Fact-Sheet\#professionals.

24. Sinnott-Armstrong W. Consequentialism [Internet]. Stanford (CA): The Stanford Encyclopedia of Philosophy (Summer 2019 Edition). 2003 May 20 [updated Jan 3 2019; cited June 23, 2020]. Available from: https://plato.stanford.edu/archives/sum2019/entries/consequentialism/. 
25. Azarpazhooh MR, Morovatdar N, Avan A, et al. COVID-19 pandemic and burden of non-communicable diseases: an ecological study on data of 185 countries. J Stroke Cerebrovasc Dis. 2020 Sep;29:105089. https://doi.org/10.1016/j.jstrokecerebrovasdis.2020.105089.

26. World Health Organization. The top 10 causes of death World Health Organization [Internet]. Switzerland: World Health Organization. 2018 May 24 [cited June 23, 2020]. Available from: https://www.who.int/news-room/fact-sheets/detail/the-top-10-causes-ofdeath.

27. Madjid M, Safavi-Naeini P, Solomon SD, Vardeny O. Potential effects of coronaviruses on the cardiovascular system: a review. JAMA Cardiol. EPub 2020 March 27:e1-e10. https://doi.org/10.1001/jamacardio.2020.1286.

28. Wang D, Hu B, Hu C, Zhu F, Liu X, Zhang J, et al. Clinical characteristics of 138 hospitalized patients with 2019 novel coronavirus-infected pneumonia in Wuhan, China. JAMA. 2020 February 7;323:1061-1069. https://doi.org/10.1001/jama.2020.1585.

29. Dyer O. COVID-19: pandemic is having "severe" impact on non-communicable disease care, WHO survey finds. BMJ. 2020 June 3;369:m2210. https://doi.org/10.1136/bmj.m2210. 